\title{
Prioritizing operational risks in container shipping systems by using cognitive assessment technique
}

\author{
Son Nguyen
}

Department of Maritime Transportation Economics, Vietnam Maritime University, Haiphong, Vietnam, and HaiYan Wang

School of Transportation, Wuhan University of Technology, Wuhan, China and National Engineering Research Centre for Water Transport Safety, Wuhan, China

\begin{abstract}
Purpose - This paper aims to propose a technique based on cognitive assessments to quantify identified operational risks from the perspective of container shipping or logistics system administrators. The results derived from the risk quantification could be used to prioritize risks as well as support the decision-making process in risk prevention and mitigation.

Design/methodology/approach - This paper identified container shipping operational risks (CSORs) from a logistics perspective. A multivariate risk evaluation mechanism by fuzzy rules Bayesian network (FRBN) was established. An improved two-level parameter set based on the failure mode and effects analysis (FMEA) was used to support the input extraction process. By feeding cognitive assessments into the model, the identified risks are evaluated based on their utility values. An illustration example and a sensitivity analysis were carried out to justify and validate the proposed model.

Findings - The highest positions in the prioritized list of CSORs in the case study are dominated by risks in the physical flow with the first three are piracy and terrorism, force majeure and port congestion. The results derived from the case study with the satisfaction of all pre-defined axioms proved the feasibility and illustrated the functionality of the proposed risk assessment and prioritization technique.

Originality/value - Controlling risk is irrefutably a significant issue of container shipping and logistics management because of the inconsistency of risk definitions and the involvement of uncertainties. The proposed risk evaluation mechanism and the identified list of CSORs could be beneficial in system management, decision-making and reliability performance.
\end{abstract}

Keywords Risk analysis, Container shipping, Bayesian network, Risk identification,

Decision support system, Operational risk, Risk prioritization

Paper type Research paper

\section{Introduction}

Despite a relatively short development history, a steadily thriving trend of the containerized shipping industry could be observed over the past few decades. A significant amount of 1.63 billion tons containerized freight volume accounted for 15 per cent of the international seaborne trade in 2015 (UNCTAD, 2015). In the process of globalization, container shipping has become the backbone of not only maritime transportation but also logistics networks (Guerrero and Rodrigue, 2014; Lam, 2013). As its gaining momentum and involvements in

(C) Pacific Star Group Educational Foundation.

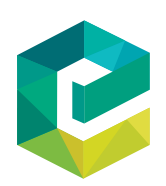

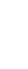


MABR

3,2

186

different grounds, container shipping companies correspondingly have to deal with challenges of instabilities and disruptions.

As originated in the nautical discipline, "risk" has always been considered as a major influencing factor in maritime transportation (Aven, 2012b; Branch and Robarts, 2014). The attention of the academia toward risk management has been reflected in numerous studies in shipping and supply chain sector (Goerlandt and Montewka, 2015b; Eleye-Datubo et al., 2006; Barnes and Oloruntoba, 2005; Soares and Teixeira, 2001). Unexpected disruptive events have both directly and indirectly negative impacts on a company in multiple aspects (Chang et al., 2015; Bichou et al., 2014; Husdal and Brathen, 2010) such as unpunctuality of the liner schedule and damages or total loss of a shipment. They could lower the transportation service quality or even cause serious disruptions in a supply chain. The continuity and agility of the shipping network and interrelated systems would be heavily affected in a pervasive manner (Yang et al., 2010). Furthermore, the existence and possible consequences of risks required a managerial mechanism, which in turn requires adequate resources of a company to be distributed (Chang et al., 2014). Considering the significant role of container shipping in transport and the irreplaceable position of the transportation process in logistics planning, risk management could be regarded as an important sector in container shipping as well as supply chain management.

Risks in the container shipping industry exist in different aspects such as business, market, supply or demand. Owing to differences in involved factors and their affecting mechanisms, this paper concentrates on operational risks. Operational risks here could be understood as the risks that originated from activities in daily operations or businesses of the company (Mitra et al., 2015). Apparently, an adequate risk management plan is essential to reduce and control operational risks. However, to facilitate risk prevention/mitigation plans, the identification and analysis of related hazardous events (HEs) are inevitable. Additionally, resources allocated for risk management of a company are obviously limited to a time frame. Container shipping corporations are not exceptions. An effectively quantitative risk analysis model will not only provide insights into the risk situation of container shipping companies but could also motivate industrial stakeholders to take actions confidently as a decision support system (Alyami et al., 2014). Nevertheless, containers shipping is a complicated and somewhat fragmented system, which comprised physical movements, the associated information and responsibilities of multiple involved parties. Therefore, a decision support system, which could prioritize the identified operational risks based on a multi-dimensional base, is crucial regarding both financial performance and service quality of a container shipping company.

Despite the importance of prioritizing operational risks, only a limited number of studies attempted to comprehensively evaluate them or contribute analytical methodologies to determine their individual relative priorities (Tummala et al., 2011; Chang et al., 2015; Chang et al., 2014). One obstacle in container shipping risk assessment/prioritization is the scale and complexity of the system per se. It involves multiple parties (such as transporters, haulers, shippers, consignees, forwarders and banks) with their responsibilities and processes (such as trucking, loading/unloading, shipping, payment and consolidating) varies with different operations, which are hard to investigate exhaustively. Bearing in mind the extraordinary relationship between container shipping and logistics operations, this paper continues to use the logistics perspective in the identification of operational HEs in container shipping as proposed in the study of Chang et al. (2015), Chang et al. (2014). By investigating the information flow, physical flow and payment flow in the logistics network, potential HEs in container shipping operations could be identified and categorized inclusively. The uncertainties attached to risks is another difficulty. It was agreed in risk 
studies that they should be carefully taken into account for an adequately systematic risk approach (Levin, 2005; Aven and Zio, 2011; Cornell, 1996). The apparent significance of dealing with uncertainties in risk analysis has also been discussed and affirmed in the literature (Aven, 2012a, 2012b; Aven, 2010; Aven, 2016). The first category of uncertainty is described by Levin (2005) as "outcome uncertainty". While the randomness in occurrence has already existed as an inherent characteristic of HEs, the impacts of a particular HE on a container shipping company are difficult to be measured. With the same HE (i.e. unpunctuality in information transmittance), the scenarios of both potential consequences and extent of severity are hard to be determined. The other category named "evidential uncertainty", has its root in the application of subjective assessment on risk quantification. Despite the advantages of the experience and knowledge background of experts as well as the ability to use various evidences in making assessments, there is still certain vagueness in their judgments if the problem is excessively complex. Therefore, a manner by which the uncertainty of assessments from experts could be reduced is necessary. Dealing with these difficulties is crucial to achieving efficient risk quantification. This paper aims at answering two research questions:

$R Q 1$. What parameters should be used to evaluate operational risks in container shipping?

$R Q 2$. How to prioritize risks in container shipping effectively considering involved uncertainties?

The rest of paper is organized as follows. An analytical literature review is presented in Chapter 2. Chapter 3 focuses on the identification of typical HEs in container shipping operations from a logistics perspective based on clear risk concept and definition. A risk evaluation model powered by Fuzzy Rules Bayesian Network (FRBN) and improved risk parameters from Failure Mode and Effects Analysis (FMEA) is proposed in Chapter 4 and validated with a case study in Chapter 5. Finally, conclusions are drawn in Chapter 6.

\section{Literature review}

A significant attention was paid toward risks in maritime transport as well as container shipping by the academia (Goerlandt and Montewka, 2015b; Chang et al., 2015; Chang et al., 2014; Alyami et al., 2014; Yang et al., 2010; Notteboom and Vernimmen, 2009; Eleye-Datubo et al., 2006; Soares and Teixeira, 2001). Not only advances and variations in risk concepts and perspectives were made for purposes, but also there were developments in applying more efficient risk analysis methodologies (Goerlandt and Montewka, 2015b; Aven, 2012b). However, there are still glitches in maritime transport risk analysis studies. In fact, the definition of risk definitely affects the result of the risk identification process. It was indicated by Goerlandt and Montewka (2015b) that one of the most foundational existing issues is the underestimation and fragmentation of risk definitions. This problem is considered as the main cause of terminological misunderstanding and limitations in riskrelated communications (Hampel, 2006; Kaplan, 1997). To clarify the base for risk identification, the used risk concept and perspective toward it in this study are introduced in Chapter 3.

In a strong frequentist viewpoint, risk evaluation strictly relies on historical statistics and objective treatments of these samples. However, this approach manner could not be implemented meaningfully in various risk assessment contexts where there is uniqueness/ randomness in the occurrence and development of potential HEs (Cornell, 1996; Apeland et al., 2002; Aven and Zio, 2011; Li et al., 2012). Additionally, as Bjerga and Aven (2015) 
MABR

3,2

188

denoted in an adaptive risk management example, the dynamics of risk should be noticed in the analyzing process. Therefore, using entirely historical, even a continuously updated data as experience-wise risk description, seems to make the analysis process always left behind by the real risk situation. In opposite, using subjective assessments in measuring risk as a constructivist approach returns a cognitive, socialized and sometimes predictive view of risks (Goerlandt and Montewka, 2015b, Apeland et al., 2002). Nevertheless, the objective existence of risks is still undeniable, and the subjectivity should only enter the scene when attempts were made to measure/analyze risks (Aven, 2012b; Aven, 2010; Aven et al., 2011). As a result, differences among risk concepts and definitions of risk levels as individual mind constructs is a difficulty in risk assessment. Risk studies that used expert assessments usually attempt to establish "standards" such as risk concept or risk measuring instruments to calibrate assessing system or use iterative elicitation procedure to limit biases (Apeland et al., 2002; Aven, 2012b). By facilitating specification in risk description and assessment, this study uses the subjective probability from judgments of experts as the primary source of inputs for the container shipping risk evaluation process.

Even though studies have been conducted on the container shipping risks, an inclusive identification of operational risks which concerns the relationship between container shipping and logistics network has just been proposed recently (Chang et al., 2015; Chang et al., 2014). Although the logistics perspective in container shipping risks identification was proved as applicable and effective, problems related to the risk analysis methodology are still observable in these studies. The risk parameters that only consist of likelihood and consequences seem excessively general and inadequate in risk evaluation. Furthermore, using risk mapping and average risk scale or stochastic dominance method where expert judgments are treated as crisp numbers without an efficient mechanism to handle uncertainties or vagueness also affects the result of risk evaluation process. This study concentrates on a more comprehensive and specific risk parameter set for risk assessment in container shipping operations from a logistics perspective.

The Failure Mode and Effects Analysis (FMEA), first developed by the US Armed Force in 1950s, is a useful assessment tool in product or system safety and reliability analysis (Carlson, 2012). The traditional risk quantification approach of FMEA used the product of likelihood, consequence severity and the probability of being undetected to prioritize risks risk priority number (RPN). Owing to its simplicity and easiness in implementation, FMEA was applied widely in the maritime sector including ship design and classification (IMCA, 2002), offshore engineering system (Yang and Wang, 2015), maritime transportation system (Goerlandt and Montewka, 2015a). There is also an FMEA review paper of Liu et al. (2013) includes 75 studies about FMEA in risk evaluation. However, this approach manner is criticized by literatures as: ignoring linguistic variables from expert (Wang et al., 2009; Garcia et al., 2005); shortage of an universal scale (Kumru and Kumru, 2013; Garcia et al., 2005); limitation of RPN as a proper and meaningful risk measurement (Kumru and Kumru, 2013). To tackle these deficiencies, methods were complementarily applied to enhance FMEA such as fuzzy set theory (Zadeh, 1965); Data Envelopment Analysis (Garcia et al., 2005); Artificial Neural Network (Rafie and Samimi Namin, 2015) and various others.

As a proposed method to enhance the risk quantification feature of FMEA, risk evaluation model of Yang et al. (2008) using Bayesian reasoning with fuzzy rules base (FRB) is proved to be effective in calculating failure priority value based on FMEA risk attributes (Alyami et al., 2014). However, its applicability is heavily affected by the bulky and arduous establishment of the IF-THEN FRB with a rational structure of degree of belief (DoB). Based on that, Alyami et al. (2014) proposed a more "automatic" and "balanced" mechanism of IFTHEN rules generation. For example: 
IF likelihood is Low; consequence severity is Low; being detected probability is Medium and impact on port resilience is High THEN risk level is Low with 50\% (2/4), Medium with 25\% (1/4) and High with $25 \%(1 / 4)$ DoB.

However, the meaning of the attribute "impact on port resilience" which was introduced as a separated factor seems to overlay with "consequence severity" as one of the multiple direct adverse effects of an HEs on the system. This overlap certainly affected the accuracy of the risk index (RI) results. The study of Yang et al. (2013) also used FRBN in prioritizing port security vulnerabilities. Nevertheless, the criticality evaluations derived as the results of the fuzzification process were limited in just two states, while in fact, the values regarding risk parameters such as "damage capability" or "recovery difficulty" could be in a much wider range. Given the existing difficulties and limitations as well as advantages of prior studies, this paper will introduce a novel risk technique which comprised an improved risk parameter structure based on FMEA and its integration into an FRBN model for container shipping risk evaluation.

\section{Operational risks in container shipping}

As an important part of risk management, risk identification is heavily affected by the used concept of risk (Aven and Krohn, 2014; Aven, 2012b). In fact, the application and significance of a risk analysis study largely depend on risk communication. However, applied risk concepts are diversified, weakly justified both in general (Aven and Zio, 2014; Aven, 2012b) and in maritime transportation particularly (Goerlandt and Montewka, 2015b). Inconsistent risk concept on top of terminological misunderstandings undeniably obstruct risk analysis models from actual effective applications. Also, an unreasonable or unjustified risk perspective could seriously misguide the decision-making process (Aven, 2012b). Answer the reasonable call of Goerlandt and Montewka (2015b), Aven (2012b) for a clearer theoretical base in risk analysis papers, the applied concept of risk is introduced before the risk identification process.

\subsection{Concept of risk - risk definition and perspective}

Numerous risk concepts have been developed throughout history. They could be traced back to different sourcing environment (such as economics and engineering). In the study of Aven (2012b), nine groups of risk definitions are classified into six development paths historically, then argued and analyzed to examine their suitableness. The result indicates that risk concepts are now developing toward a general and holistic manner, able to capture the risks in multiple disciplines. Among groups of risk definitions, $R=C \& U$ which defines risk as combination of Consequence $(\mathrm{C})$ and Uncertainty $(\mathrm{U})$ are pointed out as the most appropriate concept (Aven, 2012a; Zio, 2007; Aven, 2012b). In addition, this approach usually incorporate the HEs/threats (A) as an prior element lead to specific consequences (Aven and Krohn, 2014; Aven and Reniers, 2013; Aven, 2011). Based on this risk concept, the definitions of risk put forth by this paper will be established and used throughout this study. The specialized definition of operational risk is adapted from the study of Manuj and Mentzer (2008) with minor modification to be in line with the proposed Risk definition:

- Risk definition: The presence of potential HEs, which may lead to actual negative consequences and uncertainties involve in this transformation.

- Operational risk definition: The existence of risks which may negatively affect the internal ability of the company to maintain its goods/services at a certain level of quality, quantity or profitability. 
MABR

3,2

190

This definition describes risk as a qualitative concept by which facilitate the distinction between risk definition and measurement. The perspective toward risk of this definition is clear. It recognized the objective existence of risk as well as the uncertainty as a natural characteristic of risk. Probability here is not viewed as a component of the risk concept per se but used as a tool for risk measurement/description through informed judgments provided by multiple experts - intersubjective probability (Aven et al., 2011).

\subsection{Identification of hazardous events in container shipping operations}

The role of container transport in logistics systems is irreplaceable. For the sake of risk prioritization and prevention or responses to ensure the reliability and seamlessness of the container transport system, the existing operational risks should be identified inclusively. This problem could be solved adequately by the implementation of a logistics viewpoint toward container shipping operations. Essentially, activities in container shipping could be divided into three flows: Information, Physical and Payment (Figure 1). This study will use the manner proposed by Chang et al. (2014), Chang et al. (2015), Chang et al. (2016) to identify risk in container shipping operations systematically from previous literatures. Owing to the rarity of literature on container shipping operational risk, the reviewing process will also include operational risk studies on container logistics/container supply chain.

3.2.1 Information flow. The information flow is closely related to the visibility and collaboration performance of the logistics network as well as container shipping (Lotfi et al., 2013). The flow is initiated by the trade agreements between consignors and consignees. To assure functional connections for an operation, a complex information sharing/transmitting network is created between multiple parties in the system (Figure 1). As the development of logistics networks to provide more features such as door-to-door services, distribution processing or warehouse operations, the complexity of the information flow is also increased, put it under multiple risks (Madenas et al., 2014). By reviewing literature in the field, Madenas et al. (2014) pointed out insufficiencies of communications among heterogeneous systems such as interruptions or overlaps. Large time-lags between receipt and transmission has also been considered as another cause of information delay (Metters, 1997; Angulo et al., 2004). The number of documents and processes related to multiple activities and responsibilities of parties in container transport system exposes the system to the risk of delays, for e.g. formalities of the port authority, customs clearance and documents issuing (Bichou et al., 2014).

Figure 1.

Three flows in a typical container shipping system

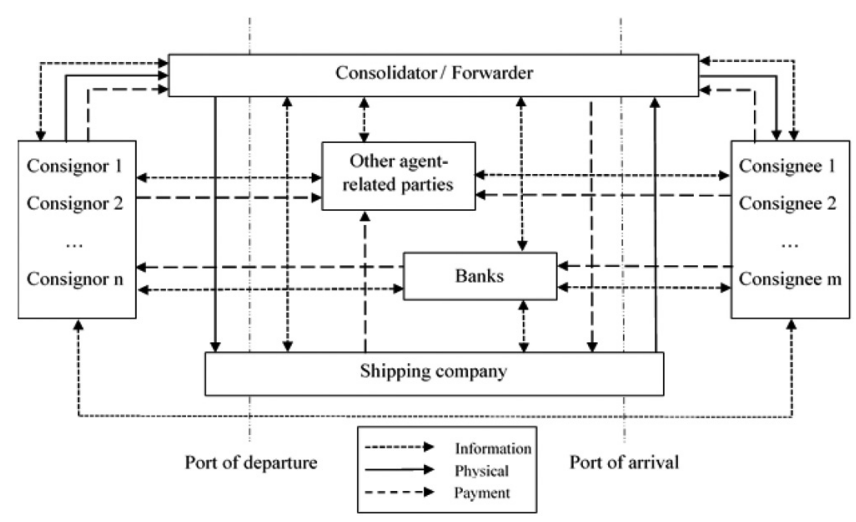


The integrity and sufficiency of information is another aspect. For example, in many cases, only a generic description of consolidated cargoes in a Less than Container Load (LCL) shipment are provided. The missing of other detailed but vital information about individual shipments may mask a risk to the ship and its crew (Bichou et al., 2014). Bichou et al. (2014) also described other cases of information asymmetry/incompleteness in documents issuing, cargoes declaration and crew's ability by which highlights the marine safety's compromises with accidents and inadequacies. Lack of information security could lead to vulnerability of the data transference. Leaked or tampered data might affect the accuracy and integrity of the information (Chang et al., 2015). Subsequently, this could expose a container shipping company to the hazard of information technology (IT) sabotage or unauthorized accesses into its database. The incompatibility of data forms using in systems is another source of data errors and inaccuracies (Tummala et al., 2011). Chang et al. (2015) also discovered that larger shippers might use their advantages in negotiation to request more, even unreasonable information from the shipping company or intentionally declare inaccurate shipment information.

IT system malfunctions could disrupt the continuity of data flow and pervasively affect other flow in a supply chain. The breakdowns of IT could be a possible factor (Tummala et al., 2011). Also, technical problems could also be triggered by human errors in interactions with the IT system, and according to Howarth (2014), 95 per cent of all IT security incidents involve human error. Inefficiencies in IT system operations will definitely put the timeliness and accurateness of the data transmission at risk.

3.2.2 Physical flow. Unlike the complexity of information flow, the actual movements of containers seem to be more straightforward (Figure 1). However, they also have to face a large number of risks, which come from multiple influencing factors including shipping density, sea condition or human errors, which could be divided into two primary categories: Transportation delay and Losses/damages of goods/assets. Transportation delays might have negative effects on the logistics cost of the shippers and also lower the liner's reputation (Notteboom, 2006). As critical nodes in the transport network, the operational performance of ports/terminals decisively affects the quality of carriage services. Notteboom (2006) identified the three typical risks in ports/terminals as in Table I. Based on the sea transportation situation in Norway, Husdal and Brathen (2010) indicated several risks that could lead to disruption of incoming and outgoing physical flow. In addition, the uncertainties in demand for empty containers and the dispatching ability of the shipping company make container shortage another risk (Song et al., 2005; Chang et al., 2015). The study of Song et al. (2005) highlighted the importance of empty containers, as well as fleet deployment, thus expressed the potential failures in capacity management. Delays could also be raised from events in which cargoes or vessels are detained by authorities e.g. customs clearance or Port State Control (PSC) inspection (Tummala et al., 2011; Bichou, 2009).

There are also HEs that could cause direct physical damages/losses to vessels, crews or goods. The consequences of these risks include human and financial losses, compromised company image, legal liabilities. Accidents and inefficiencies in the operations of both landside and seaside such as maritime collisions, road accidents, traffic jams or cargo handling operations could be considered as a substantial type of risk (Bichou, 2009; Husdal and Brathen, 2010; Goerlandt and Montewka, 2015b). Transporting containerized dangerous goods is regarded as another specific risk with its uncertain and potentially massive consequences to human, environment and infrastructures (Chang et al., 2015; Husdal and Brathen, 2010). With cold chain logistics, maintaining a specific range of temperature inside reefer containers is vital. Failures in keeping a stable and continuous electricity supply could
Container shipping systems 
MABR

3,2

\begin{tabular}{lll}
\hline Flows & Groups & HEs \\
\hline
\end{tabular}

$\mathrm{HE}$

\begin{tabular}{llll}
\hline $\begin{array}{l}\text { Information } \\
\text { risk }\end{array}$ & $\begin{array}{l}\text { Information } \\
\text { delay }\end{array}$ & $\begin{array}{l}\text { Difference in communication interface } \\
\text { (Tummala } \text { et al., 2011; Madenas } \text { et al., 2014; }\end{array}$ & ID1
\end{tabular}

risk delay

(Tummala et al., 2011; Madenas et al., 2014;

Metters, 1997; Chang et al., 2015)

192

Unpunctuality in information transmittance

ID2

(Angulo et al., 2004; Chang et al., 2015; Metters, 1997)

Unexpected delay in documents or formalities

Information inaccuracy or incompletion

Physical risk

Information technical risk

(Bichou et al., 2014; Husdal and Brathen, 2010)

Information system insecurity/vulnerability

ID3

(Chang et al., 2015)

Information asymmetry/incompleteness

(Angulo et al., 2004; Bichou et al., 2014)

Lack of information standardization and

compatibility (Tummala et al., 2011)

Extra information inquiries from shippers

(Chang et al., 2015)

Shippers hiding cargo information (non-declare)

(Chang et al., 2015; Bichou et al., 2014)

IT infrastructure deficiencies (Tummala et al., 2011)

Human errors on the IT infrastructures

(Howarth, 2014)

Transportation delay

Port strike, unrest or war situation (Notteboom,

2006; Tummala et al., 2011; Husdal and Brathen, 2010)

Port congestion (Notteboom, 2006; Bichou, 2009)

Unexpected port/terminal cargo handling

productivity (Notteboom, 2006; Tummala et al., 2011)

Unexpected slow steaming or behind voyage

schedule (Notteboom and Vernimmen, 2009;

Husdal and Brathen, 2010)

Container shortage (Song et al., 2005; Chang

et al., 2015)

Inflexibility fleet operation and management

(Song et al., 2005)

Cargos or ships being detained by authorities

(Tummala et al., 2011; Bichou, 2009)

Force majeure (Branch and Robarts, 2014;

Husdal and Brathen, 2010; Tummala et al., 2011;

Notteboom, 2006)

Loss/damage of

Inland traffic accidents and system

goods/assets

inefficiencies (Bichou, 2009; Husdal and

Brathen, 2010)

Maritime accidents (Goerlandt and Montewka,

2015b; Husdal and Brathen, 2010)

Damage to containers or cargo in cargo

II 2

II3

II4

II5

IT1

IT2

TD1

TD2

TD3

handling operations (Husdal and Brathen, 2010)

Table I.

Identified risks in

Damage caused by transporting dangerous

goods (Husdal and Brathen, 2010; Chang et al., 2015; Bichou, 2009) 


\begin{tabular}{|c|c|c|c|c|}
\hline Flows & Groups & HEs & $\begin{array}{l}\mathrm{HE} \\
\text { code }\end{array}$ & $\begin{array}{l}\text { shipping } \\
\text { systems }\end{array}$ \\
\hline \multirow{11}{*}{ Payment risk } & \multirow{5}{*}{ Payment delay } & $\begin{array}{l}\text { Damage to reefer containers because of } \\
\text { electricity failure (Chang et al., 2015) }\end{array}$ & TL5 & \multirow{3}{*}{193} \\
\hline & & Cargo being stolen or tampered (Husdal and & TL6 & \\
\hline & & $\begin{array}{l}\text { Piracy and terrorism (Chang et al., 2015; Bichou, } \\
\text { 2009) }\end{array}$ & TL7 & \\
\hline & & $\begin{array}{l}\text { Payment delay from partners or shippers } \\
\text { (Tummala et al., 2011; Chang } \text { et al., 2015) }\end{array}$ & PP1 & \\
\hline & & $\begin{array}{l}\text { Unrealized contract with partners (Notteboom } \\
\text { and Vernimmen, 2009; Chang et al., 2015; }\end{array}$ & PP2 & \\
\hline & \multirow[t]{6}{*}{$\begin{array}{l}\text { Decrease or } \\
\text { total loss of } \\
\text { payment }\end{array}$} & $\begin{array}{l}\text { Tummala et al., 2011) } \\
\text { Exchange rate fluctuation during payment } \\
\text { process (Chang et al., 2015; Tummala et al., 2011; } \\
\text { Manuj and Mentzer, 2008) }\end{array}$ & PD1 & \\
\hline & & $\begin{array}{l}\text { Unexpected rise in operational cost (Tummala } \\
\text { et al., 2011; Notteboom and Vernimmen, 2009; } \\
\text { Manuj and Mentzer, 2008; Ghosh } \text { et al., 2015) }\end{array}$ & PD2 & \\
\hline & & $\begin{array}{l}\text { Payers' financial difficulties or bankruptcy } \\
\text { (Husdal and Brathen, 2010; Tummala et al., } \\
\text { 2011; Manuj and Mentzer, 2008) }\end{array}$ & PD3 & \\
\hline & & $\begin{array}{l}\text { Shippers breaking the contract/reducing the } \\
\text { container volume (Chang } \text { et al., 2015) }\end{array}$ & PD4 & \\
\hline & & $\begin{array}{l}\text { Having partners with bad credit (Tummala } \\
\text { et al., 2011; Chang } \text { et al., 2015) }\end{array}$ & PD5 & \\
\hline & & $\begin{array}{l}\text { Containers are abandoned at the port of } \\
\text { destination (Chang } \text { et al., 2015) }\end{array}$ & PD6 & Table I. \\
\hline
\end{tabular}

heavily affect the quality of cargoes in containers (Chang et al., 2015). The risk of theft and cargo tampering are noteworthy because of its occurrence potentials in almost every process of container movements (Husdal and Brathen, 2010; Bichou, 2009). Finally, piracy and terrorism have always been considered as a well-noted security issue in maritime transport (Chang et al., 2015; Bichou, 2009).

3.2.3 Payment flow. Unlike risks in information and physical flow of the container shipping system, consequences of risks in the payment flow have direct impacts on the financial performance of shipping companies e.g. poor liquidity, distrainment. Delays of payment are mostly caused by mistakes of the payers (based on different trade terms) and unrealized contract with partners (Notteboom and Vernimmen, 2009; Chang et al., 2015; Tummala et al., 2011). Also, Tummala et al. (2011) as well as Manuj and Mentzer (2008) indicated that using weak currency in trading could cause financial losses in international businesses. Risks attached to the operational costs which are heavily affected by the fuel price are considered significant (Tummala et al., 2011; Notteboom and Vernimmen, 2009; Manuj and Mentzer, 2008; Ghosh et al., 2015). Financial difficulties or bankruptcy faced by a partner in the system also might cause payment risks to other parties (Husdal and Brathen, 2010; Tummala et al., 2011; Manuj and Mentzer, 2008). Furthermore, wrong choices of partners, which are having bad credit, might give back the partial or total loss of payments (Tummala et al., 2011; Chang et al., 2015). Break of agreement or contract, reducing container volume or intentional abandonment of containers at the port of destination also raise the 
MABR

3,2

194

Figure 2.

Improved parameter structure based on FMEA for container shipping operational risks potential of financial losses or non-payment (Chang et al., 2015). Finally, most common operational risks in container shipping are identified and listed in Table I.

\section{Risk evaluation methodology}

Bayesian subjective probability is considered as the most common method of handling epistemic uncertainty (Aven, 2016). The method applied in this study is inspired by prior studies that used FRBN to express the causal dependencies of componential factors on the overall risk level of each HE (Yang et al., 2008; Alyami et al., 2014). However, the risk measuring parameter set is improved on the basis of FMEA with the presence of two parameter levels (Figure 2). The utility values of risk levels computed from FRBN model will be used for HEs prioritization. Finally, the model will be validated by a sensitivity test.

\subsection{Improved risk parameter based on failure mode and effects analysis}

The traditional quantification approach of FMEA used only three parameters: Likelihood of occurrence (L); Severity of consequence $(\mathrm{S})$ and Probability of being detected $(\mathrm{P})$ to measure Risk level (R) by using number assignment. This approach ignored the meaningful utilization of linguistic variables in interaction with expert and lack of a universal scale, hence became severely subjective (Alyami et al., 2014; Rhee and Ishii, 2003; Garcia et al., 2005). Furthermore, the RPN is only the product of ordinal numbers and has poor performance in risk prioritization owing to results repetition. Additionally, the excessive generality presented by the traditional assessment parameters could not facilitate uncertainty treatment in the judgments assigning process. It is obviously unrealistic and infeasible for experts if the target object for assessment is excessively general or complicated (Aven, 2012b). This study will use a more accurate and tailor-made FMEA approach for container shipping by adding a secondary level of risk parameters into the existed parameter structure.

The consequences of an $\mathrm{HE}$ from the view of a shipping company could be separated into three secondary aspects: Financial impact (F), Reputational impact (I) and Operational impact (O). Financial impacts could be understood as the HE's effects on the financial flow of the company and could be expressed through financial losses e.g. fines, additional fees, loss of infrastructures and compensations. The reputational impact expresses the damages of the HEs on the company image and credibility in the view of customers or partners, which could be observed through complaints, break of contract, agreement or decrease of stock price. An HE might also affect the operational plans of a shipping company in the sense that voyage schedule could be forced to be adjusted, reallocation or intensification of human resource in response to the consequences.

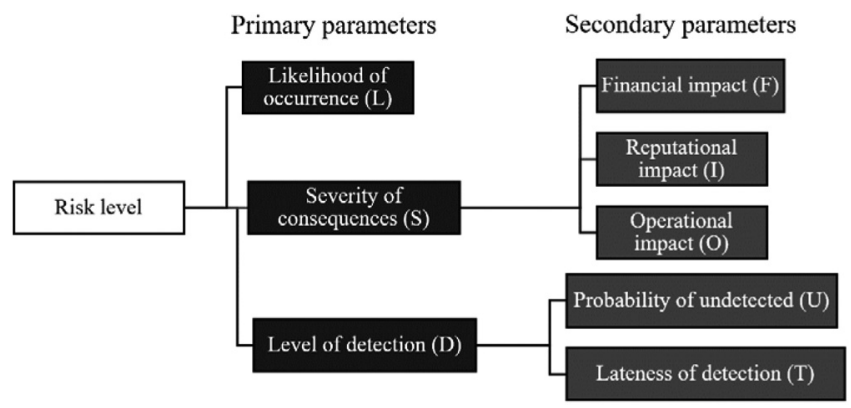


The ability of a company in HE detection is presented as Level of detection (D). A more hidden $\mathrm{HE}$ is obviously more dangerous if it is harder to be prevented and be aware of by the risk-bearers than others. In container shipping, besides the probability of being undetected $(\mathrm{U})$, the lateness of detection $(\mathrm{T})$ is also noteworthy, as it negatively affects the attempts of companies in response and limits the damages which caused by HEs. For example, lateness in the detection of missing required documents or liquidity problems could cause great financial and operational losses for a shipping company. In summary, the parameter set established for experts to assess each $\mathrm{HE}$ is as in Figure 2.

\subsection{Fuzzy rules Bayesian network model building process and risk prioritization}

To build up an FRBN model which can evaluate operational risks in container shipping, two important parts must be determined. First, the causal network structure must express the conditional relationships among related factors, especially the direct and indirect dependencies of the risk level on indicated parameters. The second component is the conditional probabilities which quantitatively convey these relationships. In this study, an IF-THEN FRB is constructed for this purpose.

4.2.1 Directed acyclic graphs building. Directed Acyclic Graphs (DAG) is an intuitive tool which provides a visual expression of a causal network (Kjærulff and Madsen, 2013). Based on the introduced risk parameter structure, DAGs which express the structure of dependency of the risk level of factors and the among factors for individual HEs could be constructed. They include two primary types of components: nodes and links. In this case, while each node is assigned to an aspect/factor, links among these nodes explain the dependencies in the causal network which follow the structure as the hierarchy graph in Figure 2. For example, the HE ID1's risk level has a DAG as in Figure 3.

In this network, the risk level of ID1 is represented by a "leaf node" which does not have any child node. All secondary parameters (F, I, O, U, T) and Likelihood of occurrence (L) are assigned to nodes that are called "root nodes", as they do not have any parent node (Yang et al., 2008). These nodes are also the gateways where the aggregated assessments are fed into the network as inputs.

4.2.2 Establishment of conditional probability tables through IF-THEN fuzzy rules base. IF-THEN rules are used in this paper as a tool to convey the quantitative conditional relationship between designated nodes. A system of IF-THEN rules based on the study if Alyami et al. (2014) could be established with a belief structure. For example:

For D, which depends on $U$ and T: IF U is Low and T is Low THEN D is Low with $100 \%(2 / 2)$ DoB, Medium with 0\% (0/2) DoB and High with $0 \%$ (0/2) DoB.

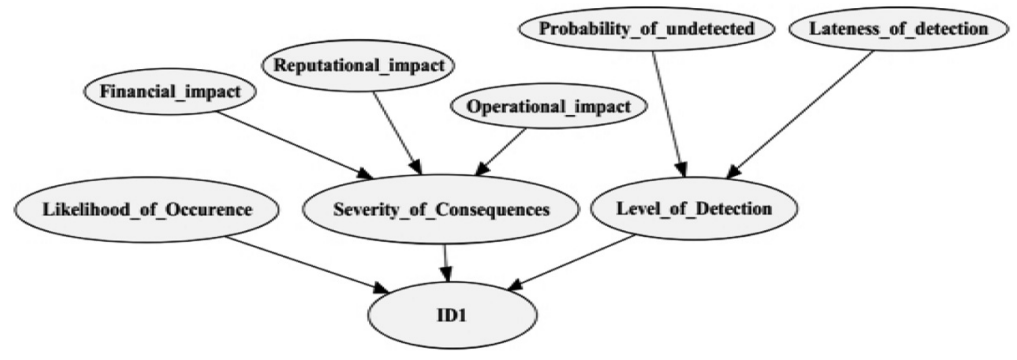

Container shipping systems 


\section{MABR}

3,2

\section{6}

For $S$, which depends on F, I and $O$ : IF F is Low, I is Medium, and $\mathrm{O}$ is Medium THEN S is Low with 33.33\% (1/3) DoB, Medium with 66.67\% DoB (2/3) and High with 0\% (0/3) DoB.

For $R$, which depends on $L, S$, and $D$ : IF $\mathrm{L}$ is Low, $\mathrm{S}$ is Medium and $\mathrm{D}$ is High THEN R is Low with 33.33\% (1/3) DoB, Medium with 33.33\% (1/3) DoB and High with 33.33\% (1/3) DoB.

As there are three states of each node in the network (low, medium and high), the number of rules for each parameter could be calculated. Level of detection (D) has nine rules $(3 \times 3)$, while severity of consequence $(\mathrm{S})$ and risk level $(\mathrm{R})$ has 27 rules $(3 \times 3 \times 3)$. Based on these rules, CPT for each child node in the FRBN could be built. An example of CPT for R in case $\mathrm{L}$ is low is in Table II.

4.2.3 Prioritization of the hazardous events using rational degree of beliefs and proposed fuzzy rules Bayesian network model. To simplify the demonstration of the calculus process, the notions of the risk parameters and nodes assigned to them are used interchangeably in this paper $(R, L, S, D, U, T, O, I, F)$. Inputs fed into the FRBNs are aggregated rational distributions as expert judgments for individual root nodes at each state (low, medium and high). Denote $r, l$, $s, d, u, t, o, i, f$ are indicators by which states of $R, L, S, D, U, T, O, I, F$ are displayed, they might take one of these three values: 1 (Low), 2 (Medium) or 3 (High). The marginal probabilities of $D$ as the child node of $U$ and $T$; $S$ as the child node of $O, R$ and $F ; R$ as the child node of $L$, $S$ and $D$ could be calculated as the equation (1), (2) and (3), respectively:

$$
\begin{array}{r}
p\left(D_{d}\right)=\sum_{u=1}^{3} \sum_{t=1}^{3} p\left(D_{d} \mid U_{u}, T_{t}\right) p\left(U_{u}\right) p\left(T_{t}\right) \\
(d=1,2,3) \\
p\left(S_{S}\right)=\sum_{o=1}^{3} \sum_{i=1}^{3} \sum_{f=1}^{3} p\left(S_{S} \mid O_{O}, I_{i}, F_{f}\right) p\left(O_{O}\right) p\left(I_{i}\right) p\left(F_{f}\right) \\
(s=1,2,3) \\
p\left(R_{r}\right)=\sum_{l=1}^{3} \sum_{s=1}^{3} \sum_{d=1}^{3} p\left(R_{r} \mid L_{l}, S_{S}, D_{d}\right) p\left(L_{l}\right) p\left(S_{S}\right) p\left(D_{d}\right) \\
(r=1,2,3)
\end{array}
$$

By getting the probability of $R$, a risk ranking index $(R I)$ could be developed by using utility values $(U V)$ for each state as the equation (4) (Alyami et al., 2014; Yang et al., 2008). This study uses $U V_{R_{1}}=1 ; U V_{R_{2}}=10 ; U V_{R_{3}}=100$ (Alyami et al., 2014). An HE with higher $R I$

Table II.

CPT of the leaf node - risk level with $\mathrm{L}$ is low

Likelihood of occurrence Severity of consequence Level of detection

Low

\begin{tabular}{lccccccccc} 
Low & 1 & $2 / 3$ & $1 / 3$ & $2 / 3$ & $1 / 3$ & $1 / 3$ & $2 / 3$ & $1 / 3$ & $1 / 3$ \\
Medium & 0 & $1 / 3$ & $2 / 3$ & $1 / 3$ & $2 / 3$ & $1 / 3$ & 0 & $1 / 3$ & 0 \\
High & 0 & 0 & 0 & 0 & 0 & $1 / 3$ & $1 / 3$ & $1 / 3$ & $2 / 3$ \\
\hline
\end{tabular}


is considered having higher risk level. Based on $R I$ values, identified risks could be prioritized.

$$
R I=\sum_{r=1}^{3} p\left(R_{r}\right) U V_{R_{r}}
$$

\subsection{Validation method}

Sensitivity analysis is one of the most popular mechanistic validation method used in FRBN studies (Alyami et al., 2014; Yang et al., 2008). Inputs fed into root nodes will be adjusted successively and resulting changes of related child nodes will be recorded. To test the reasonability of the constructed model, the tendency in variations as well as the accuracy of implemented CPTs, three axioms as follow could be used (Alyami et al., 2014; Yang et al., 2008):

(1) Axiom 1. An increase/decrease in the prior DoB of parent nodes should certainly result in a relative increase/decrease in the posterior DoBs of the child nodes and finally, the $R I$ value based on the DoB of the leaf node.

(2) Axiom 2. The total influence magnitudes of multiple probabilities adjustments of a set of nodes, which have the same effects (positive or negative) on its child nodes and the leaf node, should always be greater than the one of its any subset.

(3) Axiom 3. The tendency of variations in probabilities with any adjustment should be in accordance with the analyzed results of influencing mechanisms (positive or negative).

\section{Illustration example and methodology validation}

\subsection{Illustration example - a case study}

The structure of the expert committee is decided based on several arguments. It should be noted here that increasing the number of rational distributions for a judgment does not ensure any "accuracy" improvement. However, there are significant threats of quality degradation owing to multiple factors. Statistically, a raise of the sample size will definitely bring more noise to the model (Rae and Alexander, 2017). Furthermore, this problem could be exacerbated by the fact that the reliability of the chosen "experts" largely depends on the cognitive ability reflected in the mental models which are, in turn, heavily affected by the situation understandings as well as the accumulated experience (Rae and Alexander, 2017). Putting more in quantity instead of quality in building expert committee is, therefore, not recommended by this research. To demonstrate the application of the proposed model, a case study is carried out on an anonymous container shipping company with the participation of three experts in different positions as the study of Alyami et al. (2014).

The subject for research is a Vietnam shipping company located in Haiphong, a major port city and planned logistics center in the northern region of the country. Bulk shipping is the primary and traditional market of the company. However, short-sea container shipping between Vietnam, China or other ASEAN countries is also an important business segment that the company wants to sustain. With a total fleet of 21 vessels and 6 of them are feeder container ships, the company mainly provides its service for Japanese and Korean industrial 
MABR

3,2

198

groups. Therefore, the company is considered by the author as an acceptable case study. A questionnaire was designed to collect subjective assessments from these experts $(\alpha, \beta$ and $\gamma$ ). They all have more than ten years of experience working in container shipping field. To support the subjective assessing process, a table of concepts for individual states of each input parameter is discussed and determined deliberatively (Table III).

In the questionnaire, experts are asked to provide their subjective assessments in the form of rational distributed DoB for each state of individual identified HEs as mentioned in Section 4. Next, a simple average calculation (arithmetic mean) is used to aggregate these raw values. These aggregated DoBs from experts are used as the input for FRBN to calculate the RI value of individual HEs. The HUGIN Expert software is used in Bayesian probability calculus (Alyami et al., 2014; Kjærulff and Madsen, 2013). Input DoBs of root

\begin{tabular}{|c|c|c|c|}
\hline $\begin{array}{l}\text { Risk } \\
\text { parameters }\end{array}$ & Low & $\begin{array}{l}\text { Definition of linguistic grades } \\
\text { Medium }\end{array}$ & High \\
\hline $\mathrm{L}$ & $\begin{array}{l}\text { Rare occurrence, once every } \\
\text { six months or less often }\end{array}$ & $\begin{array}{l}\text { Occurs sometimes, from } \\
\text { twice every six months to } \\
\text { once every three months }\end{array}$ & $\begin{array}{l}\text { Often occurs, twice every } \\
\text { three months or more often }\end{array}$ \\
\hline $\mathrm{F}$ & $\begin{array}{l}\text { Slight or no impact considered } \\
\text { the return from freight or } \\
\text { below US } \$ 10,000 / \text { time }\end{array}$ & $\begin{array}{l}\text { Significant impact } \\
\text { considered the return } \\
\text { from freight or from US } \\
\$ 10,000 \text { to } 50,000 / \text { time }\end{array}$ & $\begin{array}{l}\text { Heavy impact on the return } \\
\text { from freight, causes loss or } \\
\text { above US } \$ 50,000 / \text { time }\end{array}$ \\
\hline I & $\begin{array}{l}\text { Slight or no impact on the } \\
\text { relationships (partner or } \\
\text { customer), no complaint } \\
\text { received, no observed impact } \\
\text { on the stock market }\end{array}$ & $\begin{array}{l}\text { Noticeable impact on the } \\
\text { company's relationships, } \\
\text { received complaints or } \\
\text { causes decrease in stock } \\
\text { price but considered } \\
\text { recoverable in short term }\end{array}$ & $\begin{array}{l}\text { Heavy impact on the } \\
\text { company's relationships, } \\
\text { losses of partner(s), customer } \\
\text { (s) or breaks of contract or } \\
\text { agreement, causes } \\
\text { significant decrease in stock } \\
\text { price }\end{array}$ \\
\hline $\mathrm{O}$ & $\begin{array}{l}\text { Slight or no impact on the } \\
\text { planned voyage or ship } \\
\text { schedule, reallocation or } \\
\text { intensification of personnel is } \\
\text { unnecessary }\end{array}$ & $\begin{array}{l}\text { Causes changes in the } \\
\text { planned voyage itself or } \\
\text { ship schedule of the line, } \\
\text { causes minor reallocation } \\
\text { or intensification of } \\
\text { related personnel }\end{array}$ & $\begin{array}{l}\text { Heavy impact on the } \\
\text { company's vessel } \\
\text { management operation, } \\
\text { causes changes in operation } \\
\text { plan of other ship(s) or line } \\
\text { (s), reallocation or } \\
\text { intensification of in-charge } \\
\text { personnel }\end{array}$ \\
\hline $\mathrm{U}$ & $\begin{array}{l}\text { High predictability, significant } \\
\text { chance of detection in the } \\
\text { preparation or planning stage } \\
\text { of the operation, legs or } \\
\text { voyage, the mitigation or } \\
\text { prevention methods are } \\
\text { effectively implemented }\end{array}$ & $\begin{array}{l}\text { Difficult to identify during } \\
\text { the preparation or } \\
\text { planning stage of the } \\
\text { operation, legs or voyage, } \\
\text { the mitigation or } \\
\text { prevention methods are } \\
\text { not yet implemented or } \\
\text { implemented but with } \\
\text { limited effect }\end{array}$ & $\begin{array}{l}\text { Impossible or extremely } \\
\text { difficult to foreseen during } \\
\text { the preparation or planning } \\
\text { stage of the operation, legs } \\
\text { or voyage, the mitigation or } \\
\text { prevention methods are not } \\
\text { yet discovered by the } \\
\text { operation manager nor } \\
\text { planned for implementation }\end{array}$ \\
\hline $\mathrm{T}$ & $\begin{array}{l}\text { High chance of detection } \\
\text { during the operation or at the } \\
\text { early phase when the failure is } \\
\text { about to begin or already } \\
\text { caused impacts but the } \\
\text { severity is still minor and } \\
\text { recoverable (low) }\end{array}$ & $\begin{array}{l}\text { Harder to detect, often } \\
\text { during the operation or } \\
\text { can only be detected when } \\
\text { the failure is already } \\
\text { caused medium level } \\
\text { severity (one or more in } \\
\text { three listed above) }\end{array}$ & $\begin{array}{l}\text { Impossible or extremely } \\
\text { hard to detect during the } \\
\text { operation or can only be } \\
\text { detected when the failure has } \\
\text { already caused high-level } \\
\text { severity (one or more in three } \\
\text { listed above) }\end{array}$ \\
\hline
\end{tabular}

Table III.

Concepts of individual states for each input parameter preparation or planning stage of the operation, legs or voyage, the mitigation or prevention methods are effectively implemented early phase when the failure is about to begin or already caused impacts but the recoverable (low)
Occurs sometimes, from twice every six months to once every three months m US causes decrease in stock price but considered recoverable in short term

Causes changes in the planned voyage itself or ship schedule of the line, causes minor reallocation or intensification of related personnel

Difficult to identify during the preparation or operation, legs or voyage, the mitigation or prevention methods are not yet implemented or implemented but with limited effect can only be detected when the failure is already caused medium leve three listed above)
Often occurs, twice every

Heavy impact on the return from freight, causes loss or losses of partner(s), customer (s) or breaks of contract or agreement, causes prificant decrease in stock company's vesse management operation, plan of other ship(s) or line (s), reallocation or intensification of in-charge personnel

Impossible or extremely difficult to foreseen during the preparation or planning stage of the operation, legs or voyage, the mitigation or prevention methods are not yet discovered by the operation manager nor planned for implementation Impossible or extremely hard to detect during the operation or can only be detected when the failure has already caused high-leve listed above) 
nodes as well as other nodes in the network could be displayed as a result of the calculation process. An example of the HE ID1 is presented in Figure 4.

After getting risk level in the form of DoB in three states, Equation (4) is used to calculate $R I$ values. For example, with ID1, its index value will be calculated as: $R I_{\mathrm{ID} 1}=60.74 \% \times 1+$ $26.11 \% \times 10+13.15 \% \times 100=16.3684$. All HEs identified in Table I are prioritized based on their computed RI values; the results are presented in Figure 5.

It is noteworthy that the result of the risk evaluation and prioritization mechanism will be varied in different cases. In this particular illustrative example, the dominance of risks in the physical flow group as the most critical ones are well-observed ( $70 \%$ of the top ten HEs). Specifically, the listed first three risks are:

(1) piracy and terrorism (TL7);

(2) force majeure (TD8); and

(3) port congestion (TD2).

The most crucial information and payment risks appeared at the fourth and fifth place of this list, respectively:

(4) shippers hiding cargo information (non-declare) (II5); and

(5) unexpected rise in operational costs (PD2).

While the three most significant risks in the information flow come from the "information inaccuracy or incompletion" branch (II5, II2 and II1), the contribution of the "decrease or total loss of payment" in the field of payment risks is well observed (PD2, PD3 and PD6).

The derived prioritization results show that the applied technique is feasible and functional. Thirty-three identified container shipping operational risks were assessed and prioritized without any two of them having the same rank. Based on the prioritized list as Figure 5, the shipping company could facilitate radical decisions to prevent or mitigate identified risks. Additionally, there is a categorization possibility between risk groups, which could be expressed by significant gaps. For example, the 2.611 disparity of $R I$ values between PD3 and TD7 or the 2.1742 gap between TL6 and II3. This differentiation as well suggested a division of the analyzed risks into different groups based on their priorities and $R I$ values which is also beneficial for the decision-making processes.

\subsection{Methodology validation}

By adjusting input value of the FRBN and observation of the corresponding change of the output value, the variation, as well as its tendency, are recorded to inspect and validate the proposed risk evaluation model. Taking ID1 as a testing object, DoBs of root nodes were

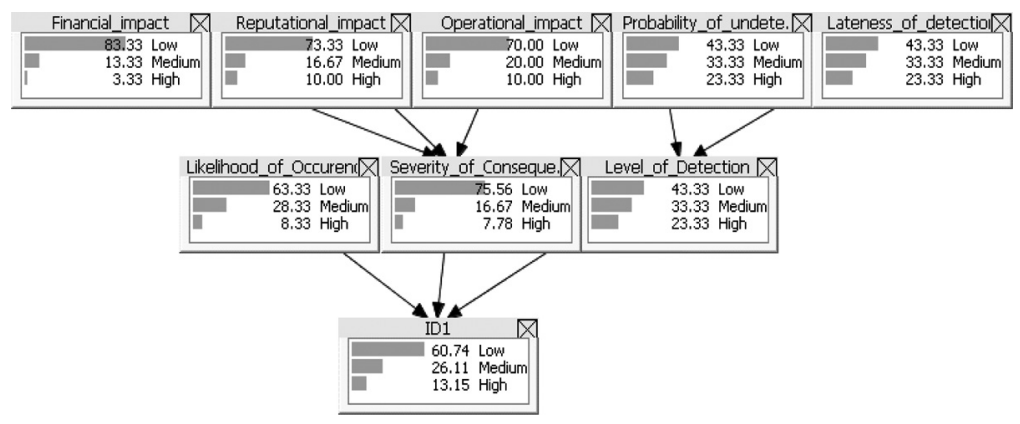

Figure 4. Risk level of ID1 calculated using HUGIN expert software 


\section{MABR}

3,2

\section{0}

Figure 5.

Prioritized list of operational risks in container shipping

\begin{tabular}{|c|c|c|c|}
\hline E code & Hazardous events & RI values & Rank \\
\hline TL7 & Piracy and terrorism & 39.7441 & 1 \\
\hline TD8 & Force majeure & 38.9377 & 2 \\
\hline TD2 & Port congestion & 38.3366 & 3 \\
\hline II5 & Shippers hiding cargo information (non-declare) & 37.9621 & 4 \\
\hline PD2 & Unexpected rise in operational costs & 37.7263 & 5 \\
\hline TL4 & Damage caused by transporting dangerous goods & 37.5948 & 6 \\
\hline TL2 & Maritime accidents & 37.5706 & 7 \\
\hline TD1 & Port strike, unrest or war situation & 37.2250 & 8 \\
\hline TL3 & Damage to containers or cargo in cargo handling operations & 36.9469 & 9 \\
\hline II 2 & Information asymmetry/incompleteness & 35.9191 & 10 \\
\hline II1 & Information system insecurity/vulnerability & 34.9984 & 11 \\
\hline IT1 & IT infrastructure deficiencies & 34.7824 & 12 \\
\hline PD3 & Payers' financial difficulties or bankruptcy & 34.3405 & 13 \\
\hline TD7 & Cargos or ships being detained by authorities & 31.7295 & 14 \\
\hline ID3 & Unexpected delay in documents or formalities & 30.8431 & 15 \\
\hline PD6 & Containers are abandoned at the port of destination & 30.6811 & 16 \\
\hline TD5 & Container shortage & 30.6532 & 17 \\
\hline TD3 & Unexpected port/terminal cargo handling productivity & 29.4661 & 18 \\
\hline PP1 & Payment delay from partners or shippers & 29.2564 & 19 \\
\hline II4 & Extra information inquiries from shippers & 28.2916 & 20 \\
\hline TL1 & Inland traffic accidents and system inefficiencies & 28.0504 & 21 \\
\hline PD5 & Having partners with bad credit & 27.8065 & 22 \\
\hline ID2 & Unpunctuality in information transmittance & 27.7507 & 23 \\
\hline IT2 & Human errors on the IT infrastructures & 26.9686 & 24 \\
\hline TD6 & Inflexibility fleet operation and management & 26.1856 & 25 \\
\hline PD4 & Shippers breaking the contract/reducing the container volume & 24.9031 & 26 \\
\hline PD1 & Exchange rate fluctuation during payment process & 24.3703 & 27 \\
\hline TL6 & Cargo being stolen or tampered & 24.0786 & 28 \\
\hline II3 & Lack of information standardization and compatibility & 21.9044 & 29 \\
\hline TL5 & Damage to reefer containers due to electricity failure & 21.4687 & 30 \\
\hline TD4 & Unexpected slow steaming or behind voyage schedule & 19.7039 & 31 \\
\hline PP2 & Unrealized contract with partners & 18.8543 & 32 \\
\hline ID1 & Difference in communication interface & 16.3684 & 33 \\
\hline
\end{tabular}

\section{Notes: No color: Physical risks; Grey: Information risks; Dark: Payment risks}

adjusted. To observe the effects of input changing in the final result, an experiment is carried out by applying absolute $\mathrm{DoB}$ in root nodes. There are two application manners of this validation method was applied: consecutive and cumulative. With the consecutive manner, the adjustments were implemented on root nodes individually, and the inputs were reset after each 
time. On the other hand, the cumulative manner applied no reset after each adjustment of root nodes. The recorded changes in the $R I$ value of $\mathrm{ID} 1$ are presented in Figure 6.

From the experiment, it is observable that the increase in both consecutive and cumulative experiment manner resulted in relatively raises of the final $R I$ value. For instance, put a 100 per cent $\mathrm{DoB}$ on the "high" state in the operational impacts node increased the $R I$ value of ID1 by 9.7002 . It seems that by the direct causal relationship, the boosting effect is strongest with the adjustment in the Likelihood of Occurrence (29.3949). It could be concluded that the proposed model satisfied the axiom 1. Moreover, in the cumulative adjustments, the continuous growth of the $R I$ values in the absolute DoBs application process proved that the axiom 2 is passed. In fact, the final rise to 100 per cent high DoB of Likelihood of Occurrence caused a surge to reach the $100 \mathrm{RI}$ value of ID1 $(16.3684+83.6316=100)$. Considering the axiom 3 , risk parameters are all have theoretically positive correlations with risk level, and all the executed adjustments showed that they behaved as expected (the rise of the inputs resulted in the positive growth of the $R I$ values). Finally, the proposed model passed the validation process, proved its feasibility and reliability by satisfying all three projected axioms.

\section{Conclusion}

This study put emphasis on operational risks identification and prioritization in container shipping from the perspective of logistics to reveal potential HEs in the pattern of containerization process and logistics network development. To prevent terminological misunderstandings or ontological misinterpretations, a clear and well-reasoned risk concept was used as the theoretical foundation for identification of existing typical HEs in container shipping operations. To overcome the deficiencies in the utilization of intersubjective assessments on excessively general or complicated problem, an improved two-level of FMEA risk model was constructed including three level 1 parameters (likelihood of occurrence severity of consequence and level of detection) and five level 2 parameters as presented in Figure 2.

Consequently, an FRBN model with a belief structure was built up, highlighted the treatment of the uncertainty in the identified CSORs through multiple supporting solutions. While expressing the extent of risks through a causal network model is a characteristic

feature of FRBN, a more specific and tailor-made parameter structure reduces the vagueness

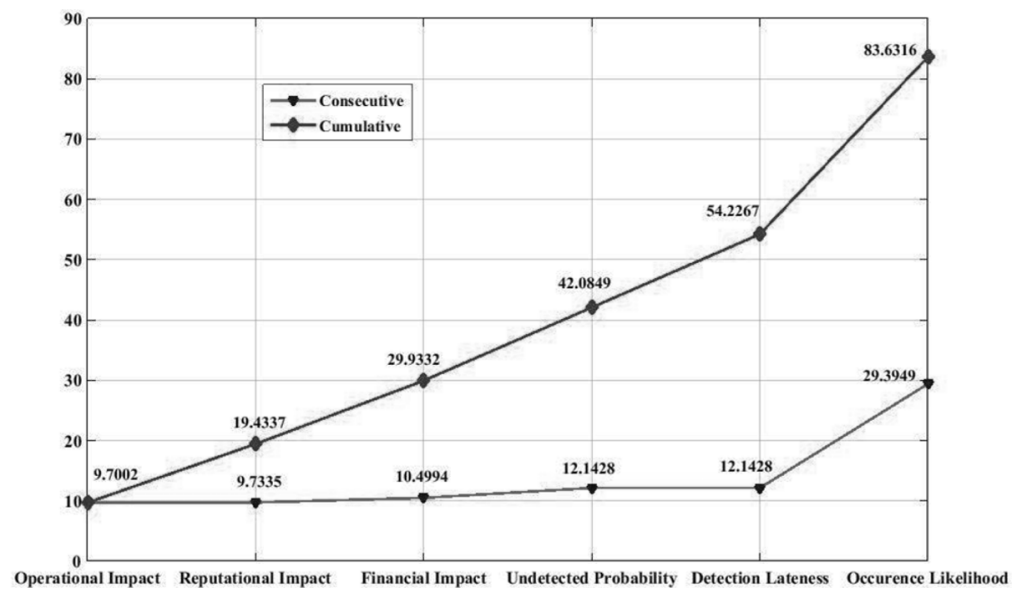

Container shipping systems

201 
MABR

3,2

202

and over-generalization in giving cognitive assessments, which is one of the main causes of epistemic uncertainty. The outcome uncertainty is handled in this model by the fuzzy rules base which expanded the coverage of the model, both parameters and risk level, to any scale through three clearly predefined states (low, medium and high). By applying the proposed model, the identified HEs could be prioritized to facilitate appropriate risk-counter methods. The feasibility of the newly developed method has been proved by the illustrative example of analyzing the risks in container shipping operation. The reliability of technique was also justified through a scientific process using the sensitivity analysis. The results derived by using this technique could be useful for the risk mitigation/prevention or related decisionmaking processes of container shipping organizations.

For example, it could be well-observed that the derived results in Figure 5 assert a serious concern about the safety and integrity of the physical status of the container fleet with the top three are:

(1) piracy and terrorism;

(2) force majeure; and

(3) port congestion.

In this case, the container shipping company could consider different insurance plans or packages with dissimilar conditions and terms Figure 7 described a list of such insurance packages. However, the recent contracts with a domestic insurance enterprise indicated that the current plan is the total loss only (TLO) option. Although the insurance fee could be minimized, the fleet of the company is exposed to significant risks of maritime collisions and piracy or terrorism. The suggested risk mitigation manner, in this case, could be changing insurance option from TLO to free of damage absolutely (FOD) or free from particular average (FPA). Another recommended option is a classification of insurance needs. For instance, valuable or detected as perilous voyages should be covered by better insurance packages.

Obviously, it is theoretically possible to apply this FRBN model on a larger scale than a company (e.g. local, national, regional or even industrial). However, it is undeniable that every shipping company has its situation of risk - risk specificity. First, the technical, financial and managerial statuses certainly vary from one company to another. Each company has its specific fleet, infrastructures, key markets and industrial standing that will never be the same as others. They also have dissimilar policies of marketing, customer relation and insurance. Second, the perspectives toward risks and the concepts of states to evaluate it (specifications of low, medium or high) are also dramatically different among companies. Rigidly apply the mechanism to investigate risks in an excessively large scale will not only affect its accuracy as a risk evaluation technique but also make the results of the prioritizing process meaningless. It is therefore recommended that this model should be best applied on an organizational scale.

Figure 7.

An example of different insurance packages

\begin{tabular}{|c|c|c|c|c|}
\hline \multirow{6}{*}{$\begin{array}{l}\text { Institute } \\
\text { Time } \\
\text { Clause } \\
\text { (ITC) }\end{array}$} & \multirow{4}{*}{$\begin{array}{l}\text { Free from } \\
\text { Particular } \\
\text { Average } \\
\text { (FPA) }\end{array}$} & $\begin{array}{l}\text { Free of } \\
\text { Damage }\end{array}$ & \begin{tabular}{|l|} 
Total Loss \\
Only (TLO)
\end{tabular} & $\begin{array}{l}\text { Total Loss; Constructive } \text { Total Loss; } \\
\text { Salvage }\end{array}$ \\
\hline & & $\begin{array}{l}\text { Absolutely } \\
\text { (FOD) }\end{array}$ & & $\begin{array}{l}\text { Sue and Labor; Collision Liability; General } \\
\text { Average (GA) }\end{array}$ \\
\hline & & & & $\begin{array}{l}\text { Partial losses caused by GA acts but } \\
\text { limited to specific components }\end{array}$ \\
\hline & & & & $\begin{array}{l}\text { Partial losses and Particular Average (PA) } \\
\text { caused by firefighting acts or collision }\end{array}$ \\
\hline & & & & Partial losses caused by GA acts \\
\hline & & & & Partial losses and PA \\
\hline
\end{tabular}


Meanwhile, some concerns with potentials for further improvements have been identified. First, the weakness of knowledge base, which could be observed in difficulties or ignorance of experts in giving assessment is still not expressed mechanically. Several questions could be raised regarding the possibility of the expert in assessing the knowledge basis of their judgments and the mechanism to effectively extract and process the input data rationally. The manner to express and control "confidence" and the existence of measurable thresholds for "acceptable confidence" in assessment activities are worthy consequent research topics that need substantial investigation. Second, a manner by which represent the customizations and expressions of relative importance among factors and experts is still not available in the proposed model. There are possibilities of injecting the vision or strategy of the system managing board into the proposed FRBN for customizations of the fuzzy rules or a weighing system for the judgments provided by the assessing committee. However, modifications of the model should be based on a reasonable theoretical foundation. Should the model follow the aggregated mental model of subjective perceptions? If the answer is No, then the factors affecting this aspect should be clarified before any customization. Undoubtedly, unsuitable or arbitrary modifications will negatively affect the reliability and effectivity of the risk quantitative model. These missing pieces could be scrutinized and supplemented by future research to enhance the risk evaluation performance.

\section{References}

Aven, T. (2010), "On how to define, understand and describe risk", Reliability Engineering \& System Safety, Vol. 95 No. 6, pp. 623-631.

Aven, T. (2011), "Selective critique of risk assessments with recommendations for improving methodology and Practise”, Reliability Engineering \& System Safety, Vol. 96 No. 5, pp. 509-514.

Aven, T., Renn, O. and Rosa, E.A. (2011), "On the ontological status of the concept of risk", Safety Science, Vol. 49 No. 1, pp. 1074-1079.

Aven, T. (2012a), Foundations of Risk Analysis, John Wiley and Sons.

Aven, T. (2012b), "The risk concept—-historical and recent development trends”, Reliability Engineering \& System Safety, Vol. 99, pp. 33-44.

Aven, T. (2016), "Risk assessment and risk management: review of recent advances on their foundation”, European Journal of Operational Research, Vol. 253 No. 1, pp. 1-13.

Aven, T. and Krohn, B.S. (2014), "A new perspective on how to understand, assess and manage risk and the unforeseen”, Reliability Engineering \& System Safety, Vol. 121, pp. 1-10.

Aven, T. and Reniers, G. (2013), "How to define and interpret a probability in a risk and safety setting", Safety Science, Vol. 51, pp. 223-231.

Aven, T. and Zio, E. (2011), "Some considerations on the treatment of uncertainties in risk assessment for practical decision making”, Reliability Engineering \& System Safety, Vol. 96 No. 1, pp. 64-74.

Aven, T. and Zio, E. (2014), "Foundational issues in risk assessment and risk management", Risk Analysis : An Official Publication of the Society for Risk Analysis, Vol. 34 No. 7, pp. 1164-1172.

Alyami, H., Lee, P.T.-W., Yang, Z., Riahi, R., Bonsall, S. and Wang, J. (2014), “An advanced risk analysis approach for container port safety evaluation”, Maritime Policy \& Management, Vol. 41 No. 7 , pp. 634-650.

Angulo, A., Nachtmann, H. and Waller, M.A. (2004), "Supply chain information sharing in a vendor managed inventory partnership", Journal of Business Logistics, Vol. 25 No. 1, pp. 101-120.

Apeland, S., Aven, T. and Nilsen, T. (2002), "Quantifying uncertainty under a predictive, epistemic approach to risk analysis”, Reliability Engineering \& System Safety, Vol. 75 No. 1, pp. 93-102.
Container shipping systems

203 
MABR

3,2

Barnes, P. and Oloruntoba, R. (2005), "Assurance of security in Maritime supply chains: Conceptual issues of vulnerability and crisis management", Journal of International Management, Vol. 11 No. 4, pp. 519-540.

Bichou, K. (2009), Port Operations, Planning and Logistics, Informa Law, Routledge, New York, NY.

Bichou, K., Bell, M.G.H. and Evans, A. (2014), Risk Management in Port Operations, Logistics and Supply Chain Security, Informa Law, Routledge, New York, NY.

Bjerga, T. and Aven, T. (2015), "Adaptive risk management using new risk perspectives - an example from the oil and gas industry”, Reliability Engineering \& System Safety, Vol. 134, pp. 75-82.

Branch, A.E. and Robarts, M. (2014), Elements of Shipping, Routledge, Taylor and Francis, New York, NY.

Carlson, S.C. (2012), Effective FMEAs: Achieving Safe, Reliable, and Economical Products and Processes Using Failure Mode and Effects Analysis, Wiley, NJ.

Chang, C.-H., Xu, J. and Song, D.-P. (2014), "An analysis of safety and security risks in container shipping operations: a case study of Taiwan”, Safety Science, Vol. 63, pp. 168-178.

Chang, C.-H., Xu, J. and Song, D.-P. (2015), "Risk analysis for container shipping: from a logistics perspective", The International Journal of Logistics Management, Vol. 26 No. 1, pp. 147-171.

Chang, C.-H., Xu, J. and Song, D.-P. (2016), "Impact of different factors on the risk perceptions of employees in container shipping companies: a case study of Taiwan", International Journal of Shipping and Transport Logistics, Vol. 8 No. 4, pp. 361.

Cornell, M.E.P. (1996), “Uncertainties in risk analysis: Six levels of treatment”, Reliability Engineering \& System Safety, Vol. 54 Nos 2/3, pp. 95-111.

Eleye-Datubo, A.G., Wall, A., Saajedi, A. and Wang, J. (2006), "Enabling a powerful marine and offshore decision-support solution through bayesian network technique", Risk Anal, Vol. 26 No. 3, pp. 695-721.

Garcia, P.A.A., Schirru, R. and Melo, P.F.F.E. (2005), "A fuzzy data envelopment analysis approach for fmea”, Progress in Nuclear Energy, Vol. 46 Nos 3/4, pp. 359-373.

Ghosh, S., Lee, L.H. and Ng, S.H. (2015), "Bunkering decisions for a shipping liner in an uncertain environment with service contract", European Journal of Operational Research, Vol. 244 No. 3, pp. $792-802$.

Goerlandt, F. and Montewka, J. (2015a), “A framework for risk analysis of maritime transportation systems: a case study for oil spill from tankers in a ship-ship collision”, Safety Science, Vol. 76, pp. $42-66$.

Goerlandt, F. and Montewka, J. (2015b), "Maritime transportation risk analysis: review and analysis in light of some foundational issues", Reliability Engineering \& System Safety, Vol. 138, pp. 115-134.

Guerrero, D. and Rodrigue, J.-P. (2014), "The waves of containerization: shifts in global maritime transportation", Journal of Transport Geography, Vol. 34, pp. 151-164.

Hampel, J. (2006), "Different concepts of risk - a challenge for risk communication", International Journal of Medical Microbiology, Vol. 296 No. 40, pp. 5-10.

Howarth, F. (2014), "The role of human error in successful security attacks". IBM, available at: https:// securityintelligence.com/the-role-of-human-error-in-successful-security-attacks/ (accessed 12 November 2015).

Husdal, J. and Brathen, S. (2010), "Bad locations, bad logistics? How norwegian freight carriers handle transportation disruptions", The World Conference for Transportation Research 2010, Lisbon.

IMCA (2002), Guidance on Failure Modes \& Effects Analyses (FMEAs), The International Marine Contractors Association (IMCA), London.

Kaplan, S. (1997), “The words of risk analysis”, Risk Analysis, Vol. 17 No. 4, pp. 407-417.

Kjærulff, U.B. and Madsen, A.L. (2013), Bayesian Networks and Influence Diagrams: A Guide to Construction and Analysis, Springer Science and Business Media, New York, NY.

Kumru, M. and Kumru, P.Y. (2013), "Fuzzy FMEA application to improve purchasing process in a public hospital", Applied Soft Computing, Vol. 13 No. 1, pp. 721-733. 
Lam, J.S.L. (2013), "Benefits and barriers of supply chain integration: empirical analysis of liner shipping”, International Journal of Shipping and Transport Logistics, Vol. 5 No. 1, p. 13.

Levin, R. (2005), Uncertainty in Risk Assessment - Contents and Modes of Communication, Doctor of Philosophy Licentiate, Royal Intitute of Technology.

Container shipping systems

Li, K.X., Yin, J., Bang, H.S., Yang, Z. and Wang, J. (2012), “Bayesian network with quantitative input for Maritime risk analysis”, Transportmetrica A: Transport Science, Vol. 10 No. 2, pp. 89-118.

Liu, H.-C., Liu, L. and Liu, N. (2013), "Risk evaluation approaches in failure mode and effects analysis: a literature review", Expert Systems with Applications, Vol. 40 No. 2, pp. 828-838.

Lotfi, Z., Mukhtar, M., Sahran, S. and Zadeh, A.T. (2013), "Information sharing in supply chain management", Procedia Technology, Vol. 11, pp. 298-304.

Madenas, N., Tiwari, A., Turner, C.J. and Woodward, J. (2014), "Information flow in supply chain management: a review across the product lifecycle", CIRP Journal of Manufacturing Science and Technology, Vol. 7 No. 4, pp. 335-346.

Manuj, I. and Mentzer, J.T. (2008), "Global supply chain risk management strategies", International Journal of Physical Distribution \& Logistics Management, Vol. 38 No. 3, pp. 192-223.

Metters, R. (1997), "Quantifying the bullwhip effect in supply chains", Journal of Operations Management, Vol. 15, pp. 89-100.

Mitra, S., Karathanasopoulos, A., Sermpinis, G., Dunis, C. and Hood, J. (2015), "Operational risk: Emerging markets, sectors and measurement", European Journal of Operational Research, Vol. 241 No. 1, pp. 122-132.

Notteboom, T.E. and Vernimmen, B. (2009), "The effect of high fuel costs on liner service configuration in container shipping", Journal of Transport Geography, Vol. 17 No. 5, pp. 325-337.

Notteboom, T.E. (2006), “The time factor in liner shipping services”, Maritime Econ Logistics, Vol. 8 No. 1, pp. 19-39.

Rae, A. and Alexander, R. (2017), "Forecasts or fortune-telling: When are expert judgements of safety risk valid?", Safety Science, Vol. 99, pp. 156-165.

Rafie, M. and Samimi Namin, F. (2015), "Prediction of subsidence risk by FMEA using artificial neural network and fuzzy inference system”, International Journal of Mining Science and Technology, Vol. 25 No. 4, pp. 655-663.

Rhee, S.J. and Ishii, K. (2003), "Using cost based FMEA to enhance reliability and serviceability", Advanced Engineering Informatics, Vol. 17 Nos 3/4, pp. 179-188.

Soares, C.G. and Teixeira, A.P. (2001), "Risk assessment in Maritime transportation", Reliability Engineering \& System Safety, Vol. 74 No. 3, pp. 299-309.

Song, D., Zhang, J., Carter, J., Field, T., Marshall, J., Polak, J., Schumacher, K., Sinha-Ray, P. and Woods, J. (2005), "On cost-efficiency of the global container shipping network", Maritime Policy \& Management, Vol. 32 No. 1, pp. 15-30.

Tummala, R., Xie, C. and Schoenherr, T. (2011), “Assessing and managing risks using the supply chain risk management process (SCRMP)", Supply Chain Management: An International Journal, Vol. 16 No. 6, pp. 474-483.

UNCTAD (2015), Review of Maritime Transport, UNCTAD.

Wang, Y.-M., Chin, K.-S., Poon, G.K.K. and Yang, J.-B. (2009), "Risk evaluation in failure mode and effects analysis using fuzzy weighted geometric mean", Expert Systems with Applications, Vol. 36 No. 2, pp. 1195-1207.

Yang, Z.L. and Wang, J. (2015), "Use of fuzzy risk assessment in FMEA of offshore engineering systems", Ocean Engineering, Vol. 95, pp. 195-204.

Yang, Z.L., Bonsall, S. and Wang, J. (2008), "Fuzzy rule-based bayesian reasoning approach for prioritization of failures in FMEA", IEEE Transactions on Reliability, Vol. 57 No. 3, pp. 517-528. 
MABR

3,2

206

Yang, Z.L., Bonsall, S. and Wang, J. (2010), "Facilitating uncertainty treatment in the risk assessment of container supply chains", Proceedings of IMarEST - Part A - Journal of Marine Engineering and Technology, Vol. 9 No. 2, pp. 23-36.

Yang, Z.L., Ng, A.K.Y. and Wang, J. (2013), "Prioritising security vulnerabilities in ports”, International Journal of Shipping and Transport Logistics, Vol. 5 No. 6, pp. 622-636.

Zadeh, L.A. (1965), "Fuzzy sets”, Information and Control, Vol. 8, pp. 338-353.

Zio, E. (2007), An Introduction to the Basics of Reliability and Risk Analysis, World Scientific Publishing.

\section{Corresponding author}

Son Nguyen can be contacted at: sonng.kt@vimaru.edu.vn

For instructions on how to order reprints of this article, please visit our website: www.emeraldgrouppublishing.com/licensing/reprints.htm

Or contact us for further details: permissions@emeraldinsight.com 